\author{
Anna ZASTAWNA-RUMIN ${ }^{1}$ \\ Katarzyna NOWAK ${ }^{2}$
}

\title{
BADANIE PRZEGRODY ZAWIERAJĄCEJ MATERIAŁ FAZOWO ZMIENNY W WARUNKACH IN SITU
}

\begin{abstract}
W artykule przedstawiono wyniki badań eksperymentalnych lekkiej przegrody zawierającej warstwę z dodatkiem materiału fazowo zmiennego. Dla tradycyjnych materiałów budowlanych wartość ciepła właściwego nie przekracza $2 \mathrm{~kJ} / \mathrm{kgK}$. Materiały zmienno fazowe charakteryzują się znacznie większą efektywną pojemnością cieplną, która $\mathrm{w}$ danym zakresie temperatury (odpowiadającej przemianie fazowej) może być nawet kilkadziesiąt razy większa. Przekłada to się na możliwość akumulowania większej ilości energii cieplnej przez taką samą ilość zastosowanego materiału. Celem stosowania materiałów ulegających przemianie fazowej $\mathrm{w}$ elementach budowlanych jest znaczne zwiększenie pojemności cieplnej obiektu przy jednoczesnym zachowaniu niskiego ciężaru konstrukcji. Pomimo dużego teoretycznego potencjału aplikacji PCM w elementy obiektów budowlanych problematyczne jest określenie ich rzeczywistej skuteczności. Charakteryzują się bowiem bardzo dużą wrażliwością na wiele czynników między innymi na warunki klimatyczne, w których zlokalizowany jest dany obiekt.

Badania wykonano dla lekkiej przegrody umieszczonej wewnątrz istniejącego pomieszczenia. Głównym celem pomiarów była weryfikacja korzystnego wpływu materiałów fazowo zmiennych na warunki termiczne w obiektach zlokalizowanych w polskich warunkach pogodowych. Przeprowadzone badania są kontynuacją analiz prowadzonych w komorze klimatycznej. Pomiar poszczególnych parametrów jest podstawą oceny wpływu materiałów fazowo zmiennych na możliwości akumulacyjne przegród w warunkach rzeczywistych.

Do tej pory wykonano liczne symulacje oraz badania w warunkach laboratoryjnych w komorze klimatycznej. Niezbędnym etapem jest weryfikacja tych rozwiązań w warunkach rzeczywistych (uwzględniająca również wpływ nasłonecznienia).
\end{abstract}

Słowa kluczowe: pojemność cieplna, PCM, akumulacja cieplna

\footnotetext{
${ }^{1}$ Anna Zastawna-Rumin, Politechnika Krakowska, ul. Warszawska 24, 31-155 Kraków, e-mail: zastawna.anna@gmail.com

2 Autor do korespondencji: Katarzyna Nowak, Politechnika Krakowska, ul. Warszawska 24, 31-155 Kraków, e-mail: kaskanowa@ poczta.onet.pl
} 


\section{Wprowadzenie}

\subsection{Opis zagadnienia}

Dla tradycyjnych materiałów budowlanych wartość ciepła właściwego nie przekracza $2,4 \mathrm{~kJ} / \mathrm{kgK}$. Materiały zmienno fazowe charakteryzują się znacznie większą efektywną pojemnością cieplną, która w danym zakresie temperatury (odpowiadającej przemianie fazowej) może być nawet kilkadziesiąt razy większa. Przekłada to się na możliwość akumulowania większej ilości energii cieplnej przez taką samą ilość zastosowanego materiału. Celem stosowania materiałów ulegających przemianie fazowej w elementach budowlanych jest znaczne zwiększenie pojemności cieplnej obiektu przy jednoczesnym zachowaniu niskiego ciężaru konstrukcji.

Pomimo dużego teoretycznego potencjału aplikacji PCM w elementy obiektów budowlanych problematyczne jest określenie ich rzeczywistej skuteczności. Charakteryzują się bowiem bardzo dużą wrażliwością na wiele czynników - między innymi na warunki klimatyczne, w których zlokalizowany jest dany obiekt. Oznacza to, że rozwiązanie bardzo efektywne w jednym przypadku może być zupełnie nieprzydatne w innym obiekcie.

Do tej pory wykonano liczne symulacje oraz badania w warunkach laboratoryjnych w komorze klimatycznej. Analiza otrzymanych wyników jest zadowalająca i sugeruje możliwość efektywnego wykorzystania tego typu materiałów w budownictwie. Niezbędnym etapem jest weryfikacja tych rozwiązań w warunkach rzeczywistych (uwzględniająca również wpływ nasłonecznienia).

\subsection{Cel podjętych badań}

Przedmiot podjętych badań stanowi przegroda zawierająca warstwę z dodatkiem materiału fazowo - zmiennego. Głównym celem pomiarów była weryfikacja korzystnego wpływu materiałów fazowo zmiennych na warunki termiczne w obiektach zlokalizowanych w polskich warunkach pogodowych. Przeprowadzone badania są kontynuacją analiz przeprowadzonych w komorze klimatycznej. Pomiar poszczególnych parametrów jest podstawą do oceny wpływu materiałów fazowo zmiennych na możliwości akumulacyjne przegród w warunkach rzeczywistych.

\subsection{Opis stanowiska pomiarowego}

Eksperyment przeprowadzono w sali dydaktycznej Politechniki Krakowskiej w okresie przerwy wakacyjnej. Stanowisko badawcze składało się z lekkiej przegrody umieszczonej w nasłonecznionym miejscu. (Rys.1) Wielkościami mierzonymi były: natężenie promieniowania padające na powierzchnię przegród (mierzone solarymetrem przymocowanym do przegrody), gęstość strumienia ciepła na powierzchni i pod powierzchnią warstwy okładzinowej 
(mierzone przy użyciu ciepłomierzy) oraz temperatura powierzchni poszczególnych warstw przegrody i powietrza wewnątrz pomieszczenia. Pomiar był przeprowadzany równocześnie dla przegrody z przymocowaną warstwą modyfikowaną materiałami fazowo zmiennymi oraz dla przegrody referencyjnej.

Aby wykluczyć wpływ zróżnicowania innych właściwości badanych materiałów na prezentowane wyniki dokonano pomiarów parametrów tj.: gęstości płyt, ich grubości, współczynnika przewodzenia ciepła (w aparacie płytowym FOX). [5]. Pomierzone parametry nie wskazują na znaczące różnice pomiędzy materiałami.

Badana przegroda ma charakter lekkiej konstrukcji składającej się z drewnianego rusztu wypełnionego 15 centymetrową warstwą wełny mineralnej. Warstwę wykończeniową stanowią płyty gipsowo - kartonowe. Na powierzchni wykończeniowej (z tradycyjnych płyt gipsowo kartonowych) dodatkowo zamocowane zostały obok siebie płyty: zwykła płyta kartonowo - gipsowa oraz płyty $\mathrm{z}$ dodatkiem materiału ulegającego przemianie fazowej $\mathrm{w}$ temperaturze 26 i $23^{\circ} \mathrm{C}$. W płycie zastosowano materiał organiczny o nazwie Micronal, który charakteryzuje się ciepłem przemiany fazowej wynoszącym $110 \mathrm{~kJ} / \mathrm{kg}$ (wg danych producenta) i stanowi około $30 \%$ udziału masowego płyty. Równoległe umieszczenie płyt zapewniało utrzymanie identycznych warunków zewnętrznych podczas pomiarów i umożliwiało bezpośrednie porównywanie mierzonych wielkości.

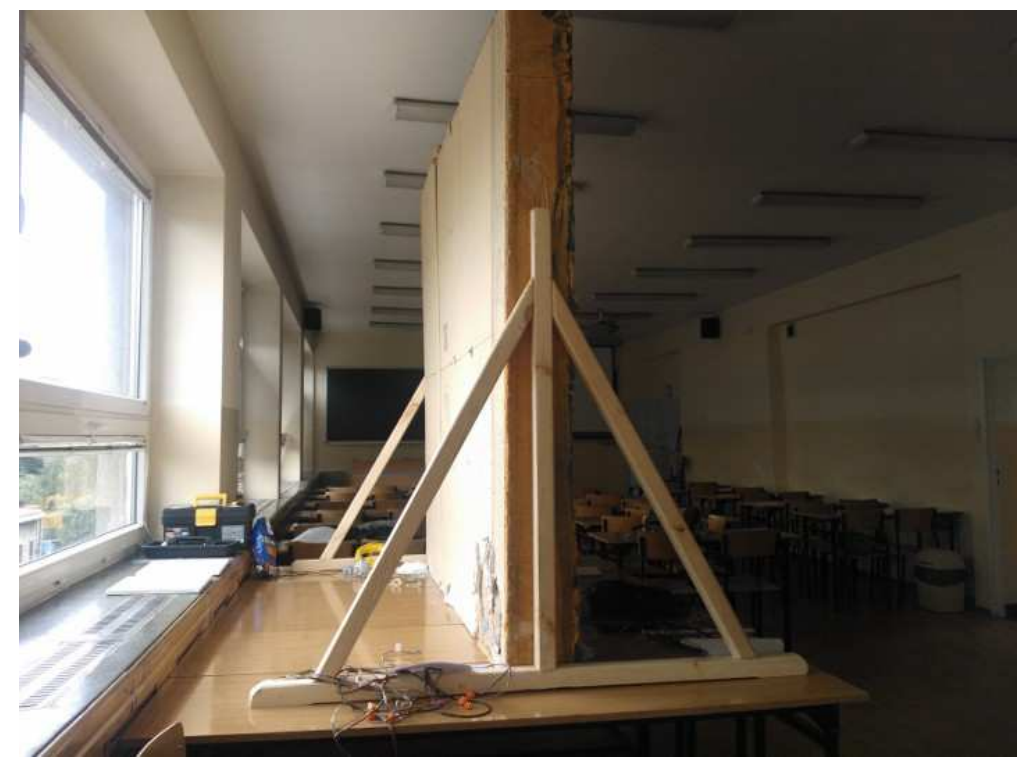

Rys. 1. Lokalizacja stanowiska badawczego wewnątrz pomieszczenia

Fig. 1. Location of a measuring position inside the premises 


\subsection{Aparatura}

Na powierzchni każdej z przymocowanych płyt umieszczono przetworniki temperatury Pt 1000 oraz ciepłomierze (rys. 2). Temperatura powietrza wewnątrz pomieszczenia (w nie nasłonecznionym miejscu w pobliżu przegrody) mierzona była przy użyciu czujnika temperatury Pt 100 . Dodatkowo mierzono solarymetrem natężenie promieniowania słonecznego docierającego do powierzchni przegrody. Rejestracja mierzonych wielkości odbywała się poprzez system zbierania danych Ahlborn Almemo podłączony do komputera. Dane pomiarowe zapisywane były przy wykorzystaniu systemu zbierania danych Data-Control 4.2. Dalsze przetwarzanie danych odbywało się $\mathrm{w}$ programie Excel.

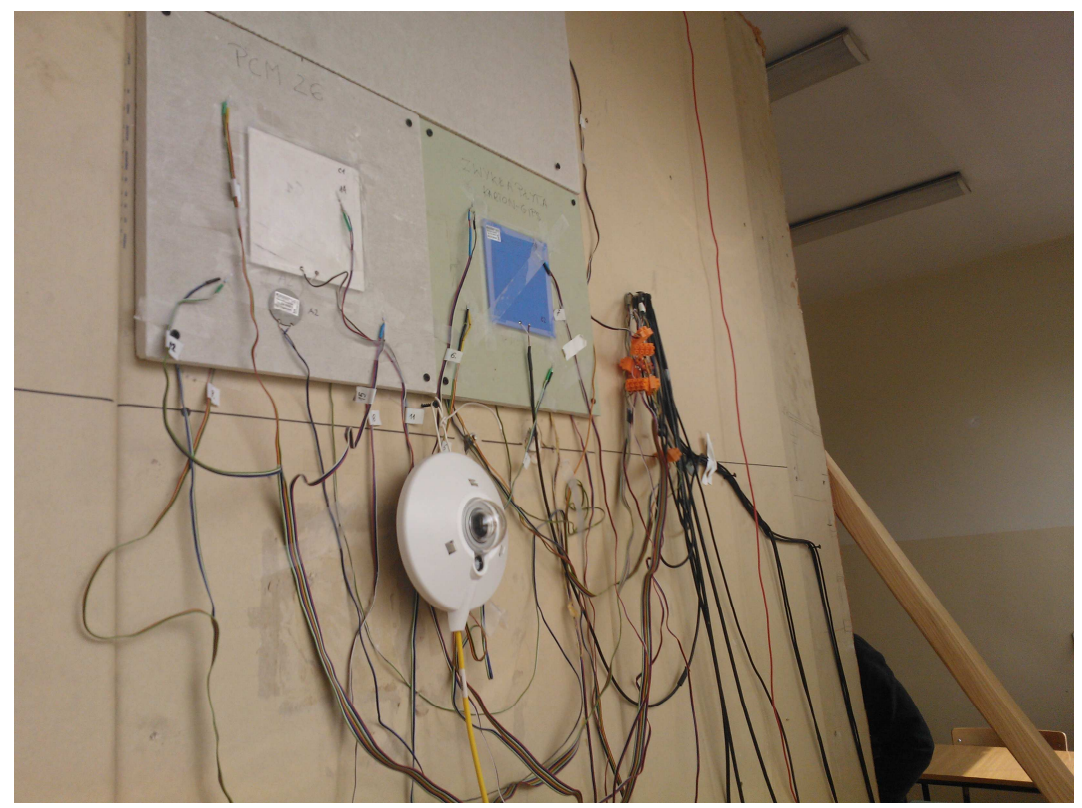

Rys. 2 Stanowisko pomiarowe $\mathrm{z}$ użytą aparaturą pomiarową (badana przegroda z płytami referencyjną i z dodatkiem PCM, na których umieszczono ciepłomierze oraz czujniki temperatury Pt 1000, poniżej widoczny solarymetr)

Fig. 2 Measuring position with the measuring apparatus (examined wall barrier with the reference board and the board containing PCM on which the heat meters and the temperature sensors Pt 1000 were placed, below - the solarymetr) 


\section{Wyniki pomiarów}

\subsection{Analiza otrzymanych wyników}

$\mathrm{W}$ artykule przedstawiono wyniki $\mathrm{z}$ pomiarów przeprowadzonych w dniach 13-17.09.2013. W czasie pomiarów płyty gipsowo-kartonowe podlegały oddziaływaniom tych samych warunków temperaturowych, co umożliwia analizę porównawczą zastosowania materiałów tradycyjnych oraz modyfikowanych poprzez dodanie PCM.

Rysunek 3 przedstawia wyniki pomiarów gęstości strumieni cieplnych z ciepłomierzy umieszczonych zarówno na jak i pod powierzchniami badanych płyt.

$\mathrm{W}$ przypadku płyty z dodatkiem materiału fazowo zmiennego maksymalne wskazania ciepłomierzy umieszczonych na powierzchni czołowej są znacznie wyższe niż w przypadku zwykłej płyty kartonowo gipsowej. Natomiast przebieg gęstości strumieni cieplnych pod powierzchniami badanych płyt wskazuje na mniejsze wartości szczytowe w przypadku płyty z PCM. W przypadku płyty referencyjnej przebiegi gęstości strumieni cieplnych zarówno na jak i pod powierzchnią płyt mają bardzo zbliżony przebieg, czyli prawie całkowity strumień

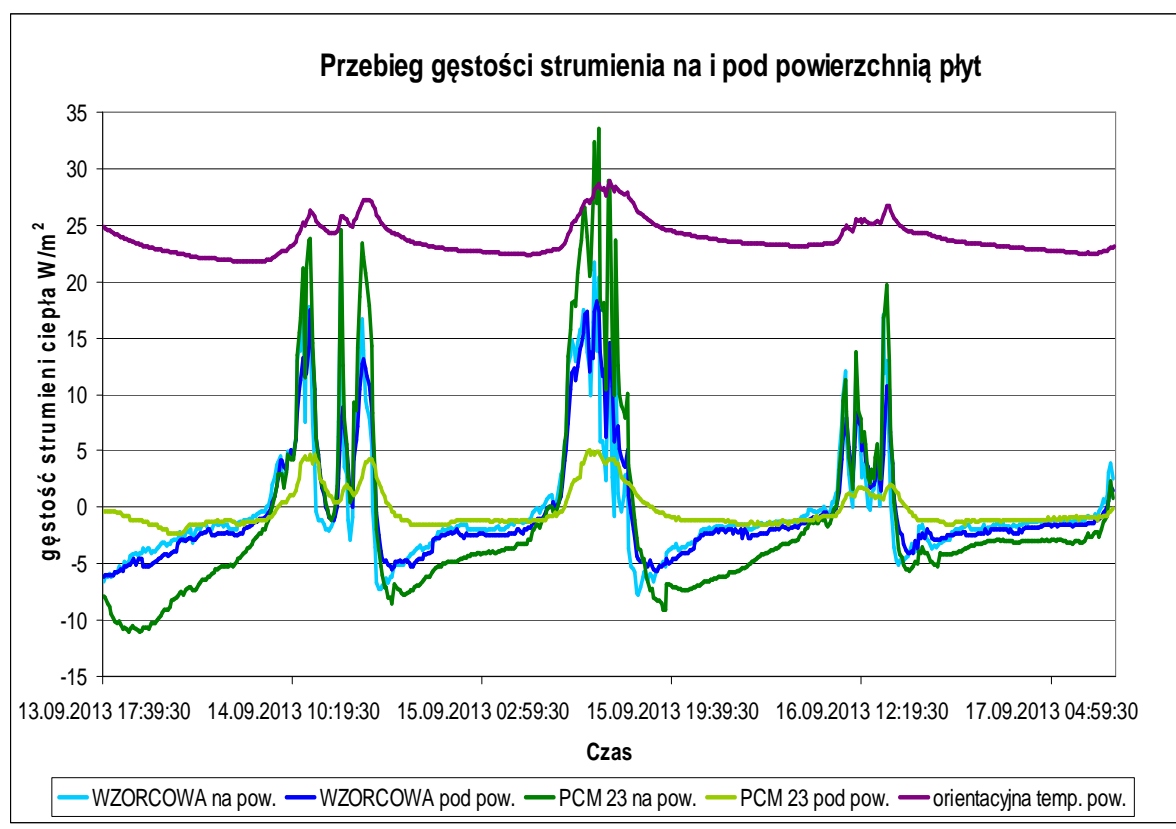

Rys. 3.Przebieg rozkładu gęstości strumieni cieplnych na i pod powierzchnią płyt gipsowo kartonowych

Fig. 3. Course of the densities of a thermal flux distribution on and under the surface of the plaster boards 
ciepła wnikający na powierzchni czołowej jest przekazywany przez powierzchnię tylną do głębszych warstw przegrody. Wskazuje to na niewielką ilość magazynowanej energii cieplnej i świadczy o większych możliwościach akumulowania energii w warstwie modyfikowanej materiałem fazowo zmiennym. Potwierdzeniem tego jest rysunek 4 obrazujący różnice w każdym kroku czasowym wskazań ciepłomierzy zlokalizowanych na i pod powierzchnią płyty zwykłej i z dodatkiem PCM, czyli ilość magazynowanej w czasie energii cieplnej wewnątrz warstwy.

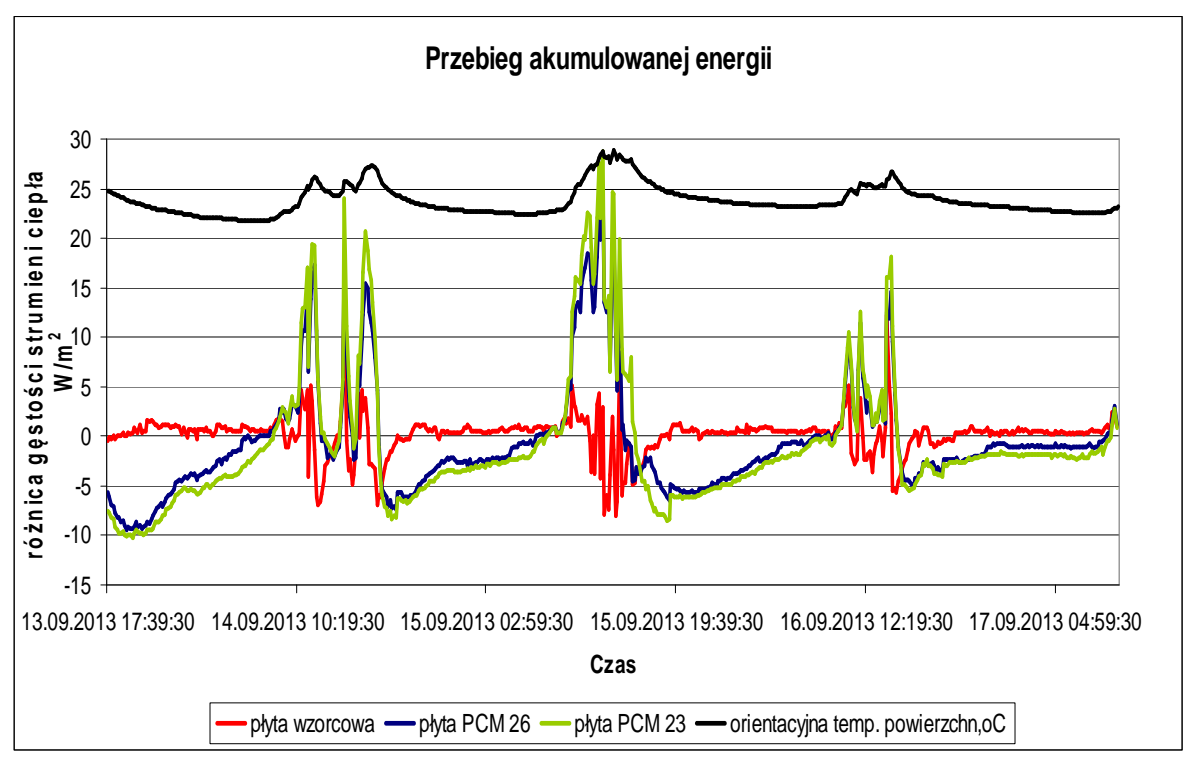

Rys. 4. Przebieg rozkładu gęstości strumieni cieplnych na i pod powierzchnią płyt gipsowo kartonowych

Fig. 4. Course of the densities of a thermal flux differences on and under the surface of the examined boards (distribution of the accumulated in time heat energy)

Wynik całkowania tych wykresów wskazuje na zakumulowanie odpowiednio ponad 4,99 i 6,25 razy większej ilości energii w płytach z materiałem fazowo zmiennym odpowiednio o temperaturze przemiany fazowej 26 i $23^{\circ} \mathrm{C}$ niż w płycie referencyjnej w analizowanym okresie czasu. W tabeli 1 zestawiono warunki klimatyczne $\mathrm{w}$ analizowanym okresie czasu - zarówno temperatura powietrza jak i nasłonecznienie osiągały umiarkowane wartości. 
Tabela 1. Warunki klimatyczne w analizowanym okresie czasu, na podstawie [7]

Table 1 Climate conditions in the studied time, based on [7]

\begin{tabular}{|c|c|c|c|c|}
\hline Data & $\begin{array}{c}\text { Temperatura } \\
\text { powietrza, } \\
\text { max./min. }\end{array}$ & $\begin{array}{c}\text { Godziny } \\
\text { słoneczne }\end{array}$ & $\begin{array}{c}\text { Max. całkowite } \\
\text { natężenie } \\
\text { promieniowania } \\
\text { słonecznego W/m }\end{array}$ & $\begin{array}{c}\text { Natężenie } \\
\text { promieniowania } \\
\mathbf{k W h} / \mathbf{m}^{\mathbf{2}}\end{array}$ \\
\hline 13.09 & $18,3 / 10,3$ & 2,1 & 812 & 2,6 \\
\hline 14.09 & $18,8 / 9,5$ & 2,2 & 904 & 2,6 \\
\hline 15.09 & $23,4 / 14,2$ & 2,9 & 835 & 3,3 \\
\hline 16.09 & $21,1 / 14,4$ & 0,4 & 916 & 1,7 \\
\hline 17.09 & $15,0 / 7,6$ & 0,0 & 269 & 0,7 \\
\hline
\end{tabular}

\subsection{Wnioski}

Uzyskane wyniki całkowania strumienia gęstości cieplnego przejmowanego przez obydwie płyty w badanym okresie czasowym wskazują na dużo większe możliwości akumulacji ciepła przez płytę z materiałem fazowo zmiennym ponad 4,99 dla PCM 26 i 6,25 dla PCM 23 razy większe niż dla płyty referencyjnej. Tak więc dla analizowanego okresu lepszą efektywność wykazuje materiał fazowo zmienny o temperaturze przemiany fazowej $23^{\circ} \mathrm{C}$.

Należy zauważyć, że zarówno temperatura powietrza zewnętrznego jak i natężenie promieniowania słonecznego nie osiągają szczytowych wartości, które mogą wystąpić podczas lata - efektywność w takim przypadku może znacznie różnić się od uzyskanej w analizowanym okresie.

Bardzo dużą zaletą magazynowania ciepła w postaci ciepła utajonego przemiany fazowej jest bierność systemu nie wymagająca dodatkowych nakładów eksploatacyjnych. Jednakże rozwiązania te wiążą się z dodatkowymi niemałymi kosztami inwestycyjnymi. W związku z tym określenie rzeczywistej efektywności ich jest warunkiem niezbędnym dla ich powszechnego stosowania.

\section{Literatura}

[1] Berrouga F., Lakhala E.K., Omaria M. El, Faraji M., Qarniac H. El.: Thermal performance of a greenhouse with a phase change material north wall, Energy and Buildings 43 (2011) 3027-3035.

[2] Chi-ming Lai, R.H. Chen, Ching-Yao Lin, Heat transfer and thermal storage behaviour of gypsum boards incorporating micro-encapsulated PCM, Energy and Buildings 42 (2010) 1259-1266.

[3] Chwieduk D., Wybrane aspekty stosowania materiałów zmiennofazowych w przegrodach zewnętrznych w polskich warunkach klimatycznych, Zeszyty naukowe Politechniki Rzeszowskiej, Budownictwo i Inżynieria Środowiska z. 59 (2/2012/II).

[4] Heim D., Clarke JA., Numerical modelling and thermal simulation of PCMgypsum composites with ESP-r. Energy Build, UK 2004;36(8):795-805.

[5] Nowak K., Zastawna-Rumin Anna.: Badanie i analiza przegrody z dodatkiem materiałów fazowo - zmiennych w warunkach niestacjonarnych, Fizyka Budowli w Teorii i Praktyce 2013, 291-296. 
[6] Oliver A., Thermal characterization of gypsum boards with PCM included: Thermal energy storage in buildings through latent heat, Energy and Buildings 48 (2012) 1-7.

[7] http://meteo.kdwd.webd.pl [dostęp 00.11.2014 r.].

[8] Rdriguez-Ubinas E., Arranz Arranz B., Vega Sánchez S., Neila González F.J, Influence of the use of PCM drywall and the fenestration in building retrofitting, Energy and Buildings 65 (2013) 464-476.

[9] Soares N., Costab J.J., Gasparb A.R., Santosc P.: Review of passive PCM latent heat thermal energy storage systems towards buildings' energy efficiency, Energy and Buildings 59 (2013) 82-103.

[10] Wnuk R.: Magazynowanie ciepła, pozyskanego z energii promieniowania słonecznego, z wykorzystaniem materiałów fazowo-zmiennych, w budownictwie, II Konferencja SOLINA 2008, Innowacyjne Rozwiązania Materiały i Technologie dla Budownictwa.

[11] Wnuk R.: Bilans energetyczny pomieszczenia ze strukturalnym, funkcjonującym $\mathrm{w}$ cyklu dobowym, magazynem ciepła z materiałem fazowo-zmiennym, Czasopismo Techniczne 2009 Z. 5. Budownictwo Z. 1-B 269-277.

\section{EXAMINATION OF A WALL BARRIER CONTAINING PHASE CHANGE MATERIAL IN SITU}

\section{S u m m a r y}

The article presents the results of examination of a wall barrier containing phase change material layer. Specific heat of the traditional construction materials does not exceed $2 \mathrm{~kJ} / \mathrm{kgK}$. Phase change materials are characterised by a higher effective heat capacity which in a given temperature range can even increase by several dozens times. It in turn leads to the ability of accumulating higher amount of heat energy by the same amount of applied material. The aim of the PCM application in building components is to significantly increase heat capacity of a building without changing its low construction weight.

Despite the fact of high theoretical potential of PCM application in the elements of the premises, it is problematic to specify their real effectiveness. These materials are characterised by a high sensitivity to many factors such as climatic conditions in which specific object is located. The examination was conducted for a wall barrier placed inside the premises. Main object of the measurements was the verification of a profitable influence of PCM on thermal conditions in the premises located in Poland. Conducted research is the continuation of completed evaluation performed in a climate chamber. The measurement of the specific parameters supports the analysis of PCM influence on the accumulation ability of wall barriers in the real conditions.

So far there have been many simulations and examinations conducted in a laboratory conditions in a climate chamber. Necessary stage is the verification of these solutions in real conditions (taking under consideration influence of the insolation).

Keywords: heat capacity, phase change material-PCM, thermal energy storage

Przestano do redakcji: $20.06 .2015 \mathrm{r}$.

Przyjęto do druku: 22.06.2015 r.

DOI:10.7862/rb.2015.88 